\title{
Contribuciones al estudio de la teoría de la empatía de Husserl en textos póstumos
}

\author{
Alan Patricio Savignano \\ CONICET/ANCBA/UBA
}

Resumen: Este artículo es un estudio acerca de la elaboración de la teoría de la empatía de Edmund Husserl. Procura reconstruir dos de los hitos principales de las reflexiones sobre la empatía en cuanto que vivencia intencional aprehensora de una subjetividad ajena, a partir de una interpretación de textos póstumos sobre la intersubjetividad editados por Iso Kern en 1973 en los volúmenes XIII, XIV y XV de Husserliana. El primer hito es la discusión que a comienzos del 1900 Husserl entabla con, por un lado, la teoría de la inferencia por analogía de Benno Erdmann -formulada originalmente por John Stuart Mill- y, por el otro, la teoría de la empatía como instinto de imitación y expresión de Theodor Lipps. El segundo es la reelaboración del concepto de empatía a partir de la fenomenología genética y el descubrimiento de sintesis pasivas a la base de los actos cogitativos del ego. Sostengo en este trabajo que estos dos jalones del pensamiento husserliano sobre la intersubjetividad no están completamente desvinculados: las nociones de analogía y de operaciones no-yoicias, tan importantes en el segundo período, estaban ya presentes a su manera en la interpretación crítica de las teorías de Erdmann/Mill y Lipps.

Palabras clave: alteridad; Edmund Husserl; empatía; fenomenología, intersubjetividad

\begin{abstract}
Contributions to the Study of Husserl's Empathy Theory in his Posthumous Texts". This is a study about the development of Edmund Husserl's empathy theory. It seeks to reconstruct two of the main milestones regarding the reflections on empathy as an intentional apprehensive experience of an alien subjectivity, from an interpretation of posthumous texts on intersubjectivity edited by Iso Kern in 1973 in volumes XIII, XIV and XV of Husserliana. The first milestone is the discussion from the early 1900s Husserl engages with, on the one hand, in relation to the theory of inference by analogy of Benno Erdmann originally formulated by John Sturart Mill - and, on the other hand, in relation to the theory of empathy as an instinct of imitation and expression of Theodor Lipps. The second is the reworking of the concept of empathy based on genetic phenomenology and the discovery of passive synthesis based on the cogitative acts of the ego. I maintain in this work that these two milestones of Husserlian thought regarding intersubjectivity are not completely unlinked: the notions of analogy and non-yoician operations, so important in the second period, were already present in their own way in the critical interpretation of theories from Erdmann/Mill and Lipps.
\end{abstract}

Keywords: alterity; Edmund Husserl; empathy; phenomenology; intersubjectivity 


\section{Introducción}

En las primeras décadas del siglo XX la pregunta por el modo en que formamos un conocimiento sobre la vida mental de los otros se volvió central en la filosofia alemana, particularmente en el ámbito fenomenológico. Entre los pensadores que se ocuparon del tema, la posteridad filosófica ha cuidadosamente guardado los nombres de Theodor Lipps (1851-1914), Max Scheler (18741928), Edith Stein (1891-1942) y, por supuesto, Edmund Husserl (1859-1938). De este último es harto conocida su teoría de la Einfühlung (traducida en general por "empatía" , aunque en ocasiones también por "endopatia" e "impatia"), según su presentación en la "Meditación quinta" de Meditaciones cartesianas (1931). Este libro, fruto de las conferencias introductorias de la fenomenología dadas en la Universidad de la Sorbona el 23 y el 25 de febrero de 1929, presenta la empatía como un tipo de acto aperceptivo singular, constituido originariamente a partir de una transferencia analogizante pasiva del sentido de corporalidad viviente o propia (Leiblichkeit) a un cuerpo ajeno (Fremdkörper) percibido ${ }^{2}$. La verificación de esta apercepción originaria se desarrolla posteriormente gracias a la asistencia de la imaginación, la cual permite, modificando la experiencia personal, transportarse imaginariamente dentro del cuerpo del otro y vivir sus vivencias como si fuesen las propias.

En 1973 se publica una serie de textos póstumos de Husserl de 1905 a 1935 sobre la intersubjetividad, editados por Iso Kern bajo el nombre de Zur Phänomenologie der Intersubjektivität (Sobre la fenomenología de la intersubjetividad), en los tomos XIII, XIV y XV de la colección Husserliana. Estos tres volúmenes, que compilan unas 1715 páginas de escritos, atestiguan el continuo interés del autor sobre el fenómeno de la pluralidad de las conciencias y las

\footnotetext{
1 El término "Einfühlung" fue traducido por primera vez al inglés como "empathy" -a partir del vocablo griego $\varepsilon \dot{\mu} \pi \alpha \dot{\theta} \theta \varepsilon \alpha$ - por el psicólogo Edward Tichener en Lectures on the Experimental Psychology of the Thought-Processes (1909). "Empathy" y, en español, "empatía" restituyen con éxito el significado de "sentirse dentro de" que posee el original alemán.

2 Los vocablos alemanes de "Leib" y "Körper" para referirse al cuerpo gozan, como es bien sabido, de una distinción técnica en el vocabulario filosófico de Husserl. "Leib", que traduciremos como "cuerpo vivo" o "cuerpo viviente" para distinguirlo, denota el cuerpo como organismo vivo cuya experiencia inmanente tiene rasgos distintivos que serán descritos en la sección 2.4 de este artículo. En cambio, "Körper" refiere al cuerpo como parte de la naturaleza física, es decir, un miembro más de la cadena mecánico-causal que rige a los objetos externos del mundo.
} 
incesantes reformulaciones de su concepción sobre el tema. Tal como afirma el intérprete danés Dan Zahavi, la amplia extensión de textos sobre el asunto y el largo período de tiempo que estos abarcan sugieren que la intersubjetividad siempre fue un problema para Husserl a lo largo de su vida y que posiblemente nunca haya llegado a una solución completamente satisfactoria al respecto ${ }^{3}$.

La aparición de los tres tomos de Husserliana mencionados ha permitido conocer la historia de la teorización de la vivencia intencional encargada de fundamentar ni más ni menos que la objetividad del mundo ${ }^{4}$ y constituir una primera trascendencia verdadera ${ }^{5}$ en el flujo de conciencia del sujeto. A propósito de la evolución de la empatía husserliana a lo largo de los años, uno de los hitos más relevantes fue sin duda la discusión que entabló Husserl, registrada en textos de 1905 a 1910, con otras teorias rivales que también pretendian explicar el acceso a una conciencia ajena: en particular, el enfrentamiento con la teoría de la inferencia por analogía (Analogieschlusstheorie) de Benno Erdmann (1851-1921) y la teoría de la empatía (Einfühlungstheorie) como imitación instintiva (Nachahmungstrieb) de Theodor Lipps. Un segundo hito de importancia tuvo lugar alrededor de 1920 con el descubrimiento desde un enfoque genético de síntesis pasivas que condicionan y posibilitan la actividad yoica de la conciencia. Este suceso en el campo de la intersubjetividad significó comprender la génesis fenoménica de la empatía en términos de un emparejamiento o una parificación (Paarung), esto es, un género particular de apercepción asociativa que se realiza sin participación activa del ego.

En este artículo quisiera exponer ordenada y claramente estos dos jalones de las reflexiones husserlianas sobre el modo de donación de una conciencia ajena. En un primer momento, desarrollaré las críticas de Husserl tanto a la teoría de la inferencia por analogía como a la teoría de la imitación instintiva en el marco de una fenomenología estática ${ }^{6}$. En un segundo momento, presentaré el descubrimiento de operaciones pasivas a la base de la empatía. El objetivo

\footnotetext{
3 Zahavi, D., Self and Other: Exploring Subjectivity, Empathy, and Shame, Nueva York: Oxford University Press, 2014, p. 124.

4 Cf. Meditaciones cartesianas, §48 ("La trascendencia del mundo objetivo, de orden más alto que la trascendencia primordial"); Lógica formal y lógica trascendental, §96 ("La problemática trascendental de la intersubjetividad y el mundo intersubjetivo").

5 Cf. Hua XIV, p. 8. La sigla Hua, con indicación de tomo y página, corresponde a Husserl, Edmund, Gesammelte Werke-Husserliana, 40 vv., Biemel, W. y otros (eds.), Dordrecht: Springer (con anterioridad, Kluwer Academic Publishers y Martinus Nijhoff), 1950-2009.

6 La fenomenología estática analiza la vida trascendental como algo acabado, obviando las leyes trascendentales genéticas de desarrollo de la misma en el curso temporal. Por lo tanto, estudia la constitución de los objetos y las vivencias como si fueran unidades completas, que pueden ser clasificadas sistemáticamente en tipos ideales ( $c f$. Meditaciones cartesianas, §37 y Hua XV, p. 41).
} 
final de este trabajo es demostrar que estas dos cuestiones no están enteramente desconectadas entre sí, como pudiese parecer a simple vista. En efecto, la comprensión de la empatía como una operación consciencial originariamente pasiva permitió a Husserl recuperar para sí mutatis mutandi ideas genuinas de las dos teorías ya descartadas y superadas. Veremos, concretamente, que un proceso de analogización por semejanza similar al pensado por Erdmann tiene un papel imprescindible en la empatía husserliana, aunque ya no como inferencia lógica o, dicho de otro modo, como juicio judicativo de orden superior. Asimismo, de la originalidad de Lipps de entender la empatía como un instinto (Instinkt) o una pulsión (Trieb), la doctrina husserliana conserva la disposición de considerar la Einfühlung como un acto que originariamente no dependen ni del consentimiento ni de la atención de un yo despierto, sino que se realiza subterráneamente de manera pasiva en la percepción de un cuerpo ajeno.

\section{Críticas de Erdmann y Lipps en los escritos póstumos de Husserl de 1905-1910}

Ciertamente los primeros intentos de Husserl de pensar el tipo de vivencia que aprehende una subjetividad ajena están marcados por la revisión crítica de las dos teorías dominantes sobre el tema en psicología y filosofia durante los inicios del 1900: la teoria de la inferencia por analogía y la teoría de la Einfühlung como imitación instintiva. Ambas teorías son criticadas y rechazadas por igual: la primera por confundir un acto aperceptivo primario con una inferencia lógica sin fundamentos sólidos; la segunda, por reducirlo a una mera percepción de sí, un acto enteramente intuitivo, producto de tendencias instintivas inexplicables y, además, restringir la cuestión del conocimiento de la alteridad subjetiva al ámbito de la expresión. A continuación, desarrollaremos por orden las respectivas denuncias de Husserl a estas concepciones.

\subsection{La teoría de la inferencia por analogía de Benno Erdmann y John Stuart Mill}

Husserl tempranamente expresa un ferviente rechazo de la teoría del razonamiento por analogía al tacharla de "sofisma fundamental" en el Apéndice IX de Husserliana XIII, datado en 1907-1908. En realidad, esta doctrina ya contaba en esos años con una larga lista de adversarios acérrimos. El primero y más importante entre ellos fue sin duda Theodor Lipps, pero no carecen de importancia las contribuciones críticas de Max Scheler y de Edith Stein. Esta

7 Hua XIII, p. 36. 
última, en su tesis doctoral publicada en 1917 bajo el título de Sobre el problema de la empatía, nos advierte sobre la popularidad que en aquel entonces ostentaba esta concepción: "La doctrina casi en general reconocida sobre el nacimiento de la experiencia de la vida anímica ajena era, antes de las impugnaciones por Lipps, la teoría de la inferencia por analogia". Los inicios de esta doctrina se remontan hasta John Stuart Mill (1806-1873), quien es reconocido como el primero en formularla de manera explícita9 ${ }^{9}$ En el apéndice mencionado, Husserl arremete particularmente contra un continuador de las ideas de Mill acerca del conocimiento de los otros sujetos, Benno Erdmann.

En su libro Wissenschaftliche Hypothesen über Leib und Seele (Hipótesis científicas sobre el cuerpo y el alma) de 1907, Erdmann sostiene que conocemos la mente y los estados psíquicos ajenos por medio de un razonamiento de tipo lógico. Los estados mentales ajenos (sensaciones, emociones, representaciones, etcétera) son hipótesis que yo formulo sobre otro sujeto en razón de la semejanza externa que hay entre la conducta de su cuerpo y la de mi cuerpo al momento de vivenciar internamente tal o cual estado mental dentro de mí. Para comprender correctamente cómo funciona este razonamiento, conviene traer a colación el desglose analítico que Karsten Stueber ofrece del razonamiento en la Enciclopedia de Filosofia de Stanford (s.v. Empathy). Según Stueber, la inferencia consta de tres premisas (i-iii) y su conclusión (iv), como puede verificarse a continuación:

“i.) Otra persona $X$ manifiesta un comportamiento externo de tipo $B$.

ii.) En mi caso, un comportamiento de tipo $B$ es causado por el estado mental tipo $M$.

iii.) Si el comportamiento de tipo $B$ es similar tanto en el caso de $X$ como en mi caso, este debe tener causas mentales internas similares (por ende, se supone que las demás personas y yo somos psicológicamente parecidas en un sentido relevante).

Por lo tanto, el comportamiento de la otra persona (el comportamiento de $X$ ) es causado por el estado mental de tipo $M{ }^{\prime \prime}{ }^{\prime \prime} 11$.

\footnotetext{
8 Stein, E., Sobre el problema de la empatía, Caballero Bono, J.L. (trad.), Madrid: Trotta, 2004, p. 43.

9 Cf. Mill, J.S., An Examination of Sir William Hamilton's Philosophy, Londres: Longman, Green \& Co., 1865, pp. 190-191.

${ }^{10}$ Stueber, Karsten, "Empathy", The Stanford Encyclopedia of Philosophy (Spring 2017 Edition), Edward N. Zalta (ed.), URL = <https://plato.stanford.edu/archives/spr2017/entries/empathy/ > .

${ }^{11}$ Las citas de textos en lenguas extranjeras están directamente traducidas por mí a menos que se indique lo contrario.
} 
Este razonamiento pretende explicar la manera en que atribuimos, por ejemplo, a alguien (persona $X$ ) el estado emocional del enojo (estado mental $M$ ). Observo primero en la fisonomía de $X$ que su ceño se frunce, sus músculos se tensan, su tono de voz se agrava y eleva (comportamiento externo tipo $B$ ). Dado que yo mismo efectué en varias ocasiones una conducta de tipo $B$ en los momentos que sentía el estado interno $M$, deduzco por medio de una analogía que la otra persona experimenta en este momento un estado de tipo $M$. De esta manera, la apariencia y la conducta del cuerpo ajeno cumplen la función de síntomas o signos externos de presuntos estados mentales internos del otro sujeto deducidos por mí inferencialmente.

\subsection{Críticas a la teoría de la inferencia por analogía}

A propósito de la teoría de Erdmann/Mill, Husserl se pregunta con tono escéptico en el apéndice mencionado previamente: “¿Podemos razonar de la siguiente manera: yo encuentro mi yo asociado a un cuerpo vivo (Leib); ahora bien, el cuerpo vivo ajeno es análogo al mío, por tanto, un yo debería igualmente estarle asociado?... ¿Esto no presupone que yo pueda encontrar el yo ajeno asociado al cuerpo vivo ajeno exactamente tal como mi yo lo está a mi cuerpo propio?... ¿este razonamiento tendría algún sentido, si yo no tuviera ya una experiencia de mí mismo y de los otros y, por consiguiente, si yo no tuviera ya una razón inmediata para practicar esta distinción?”12.

Como se dijo más arriba, Husserl juzga la inferencia analogizante como un sofisma fundamental. Particularmente, el razonamiento de Erdmann/Mill sufre, según Husserl, de una suerte de petición de principio, esto es, presupone que existen ciertos objetos físicos en el mundo que tienen la cualidad particular de ser cuerpos animados por un yo psíquico. El razonamiento esconde como presupuesto lo que en verdad debería concluir: la existencia de entidades que exhiben una unidad psicofisica entre un cuerpo y una mente, en las cuales se daría un influjo mutuo entre los dos elementos del compuesto. Así, el problema principal de esta teoría es que no se pronuncia acerca de cómo un cuerpo vivo es entendido como tal, esto es, a título de sustrato material de un sujeto psíquico.

Vale aclarar aquí un punto importante antes de seguir avanzando. Husserl, exactamente al igual que Lipps, pretende que la teoria de la inferencia analógica se ofrezca como una teoría genética sobre el conocimiento de los otros. Esto quiere decir que esta doctrina debería dar una explicación del origen de

${ }^{12}$ Hua XIII, pp. 36-37. 
nuestro saber sobre otros sujetos. Sin embargo, es posible sostener que este no es el caso. Stein tiene el mérito de haber aclarado que "la intención de la teoría [de la inferencia por analogía] no es propiamente una explicación genética"13. Su objetivo es, en cambio, explicar cómo atribuimos estados mentales particulares a otras personas, es decir, de qué manera llegamos a saber que alguien está enojado, alegre, meditabundo, dolorido, etcétera, y no, por ende, justificar la atribución de conciencias, mentes o almas a cuerpos mundanos, ni mucho menos aun formular las condiciones de posibilidad de la aparición fenoménica de un otro. Sin embargo, a pesar de una posible confusión de Lipps y Husserl respecto de las pretensiones teóricas de la inferencia analógica, la omisión de una respuesta a la cuestión genética por parte de los defensores de esta doctrina sigue siendo una falta grave. Efectivamente, la misma Stein afirma que, a causa de la ausencia de una respuesta al problema genético, las tesis de Erdmann/ Mill son peligrosamente compatibles la suposición de que vivimos rodeados de cuerpos físicos sin alma y sin vida, pero con comportamientos externamente similares a los nuestros ${ }^{14}$.

En una nota del Apéndice IX ya mencionado, Husserl confiesa que en lo que respecta a las principales críticas contra la teoría del razonamiento por analogía, él solo parafraseó las denuncias de Lipps ${ }^{15}$. Esto es comprensible por el hecho de que Lipps fue el principal responsable de volver obsoleta la teoría fundada por Mill a comienzos del siglo pasado. La ausencia de una respuesta genética y la caída en una falacia de petición de principio ya habían sido remarcadas por él en su Leitfaden der Psychologie (Manual de la psicología) (1903) -obra de referencia para Husserl en sus notas publicadas póstumamente- y Lipps vuelve a repetir las críticas de manera más sistemática en un artículo posterior titulado "Das Wissen von Fremden Ichen" (El conocimiento de otros yoes) (1907).

En el artículo de 1907, el entonces catedrático de la Universidad de Múnich señala un segundo error grave de la teoría de la inferencia analógica. Esta presupone equivocadamente una asociación simple entre mis estados mentales y una representación externa de mi cuerpo. Esta asociación entra en juego en la premisa (ii) del desglose de Stueber y resulta indispensable para el razonamiento. Sin embargo, las sintesis asociativas entre cierta imagen óptica de mi cuerpo, o de una parte de él, y cierto estado interno de mi mente no son

13 Stein, E., Sobre el problema de la empatia, p. 44.

14 Cf. ibid., p. 43.

15 Cf. Hua XIII, p. 36. 
tan simples, advierte Lipps. En efecto, la mayoría de las veces, durante nuestra experiencia de un estado mental interno (por ejemplo, ira) no tenemos simultáneamente una representación externa de nuestro cuerpo (por ejemplo, una imagen óptica del fruncimiento de nuestro ceño). Una imagen visual y externa del cuerpo no acompaña generalmente la vivencia de una emoción. Nuestra fisionomía facial casi siempre se mantiene oculta a nuestros ojos durante una experiencia emocional. Esto refuta la afirmación de la premisa (ii) acerca de que yo siempre poseo el conocimiento de una unión causal entre $B$ y $M$.

Sin embargo, agrega Lipps, sí tenemos una conciencia inmediata de diversas sensaciones kinestésicas de nuestra piel y de nuestros músculos durante ciertos estados mentales. Este tipo de sensaciones son de índole muy distinta a las visuales. Por lo demás, Husserl dirá que ellas constituyen la "capa estesiológica" del cuerpo propio ${ }^{16}$, uno de los estratos más fundamentales del yo psicofisico, y son el objeto de una percepción somática de nuestro cuerpo ${ }^{17}$, a diferencia de una percepción externa, óptica y física del mismo ${ }^{18}$.

En resumen, en los años de 1907-8, Husserl arremete contra la teoría de la inferencia por analogía defendida por Erdmann, reproduciendo sin grandes modificaciones algunas réplicas ya formuladas por Lipps. No obstante, de este último solo hace suya la pars destruens de su teoría sobre la Einfühlung. Como veremos de inmediato, Husserl también descalifica la teoría lippsiana de la empatía entendida como una combinación de instintos de imitación y de expresión.

\subsection{La teoria de la empatía como instinto de expresión e imitación de Theodor Lipps}

Contrariamente a quienes sostienen que nuestro saber sobre la vida mental de los otros depende de una inferencia, Lipps afirma que el acceso a un yo ajeno se realiza por medio de una actividad instintiva o impulsiva (Triebtätigkeit) que él denomina "empatia" (Einfühlung). Se trata de un mecanismo natural que el ser humano comparte de cierto modo con otras especies animales. No forma parte en absoluto de la esfera de las actividades cognitivas racionales, sino del

16 Cf. ibid., pp. 30-33.

17 Cf. Hua XIV, p. 56.

${ }^{18}$ Cabría preguntarse en otra ocasión acerca de la relevancia de estas consideraciones de Lipps en la elaboración teórica del concepto de cuerpo vivo (Leib) en Husserl, noción que es desarrollada principalmente en el tomo II (póstumo) de Ideas relativas a una fenomenología pura y una filosofía fenomenológica y en los volúmenes de Husserliana acerca de la intersubjetividad aquí revisados. 
conjunto de tendencias automáticas, involuntarias e irreflexivas del sujeto. Lipps es contundente al respecto: "Empatía no es el nombre de una inferencia, sino el nombre de un hecho (Tatsache) original e irreductible, al mismo tiempo que increíblemente maravilloso"19. Este hecho (instintivo) es considerado por él un concepto básico de la psicología y la sociología ${ }^{20}$ : básico en el doble sentido de central y de estrato último del análisis del modo de captación de una subjetividad extraña.

Lipps describe esquemáticamente la aprehensión de estados mentales de otro sujeto por medio de la empatía con las siguientes palabras: "Veo el gesto del otro y lo aprehendo mentalmente, o soy aprehendido en él. Y, mientras soy en él, hay una tendencia en mí a producir ese gesto, i.e. la tendencia de realizar corporalmente una actividad. Sin embargo, esta tendencia es... una y la misma cosa que el sentimiento de ira, está inmediatamente atada a este estado emocional. Por ende, el estado emocional está inversamente vinculado al impulso de producir corporalmente aquel proceso"21.

Para entender esta descripción del mecanismo completo de la empatía, debemos antes bien explicar los dos procesos subyacentes que actúan de manera combinada y simultánea en ella, a saber, el instinto de imitación (Nachahmungstrieb) y el instinto de exteriorización (Äußerung) o de expresión (Ausdruck). Ambos pueden analizarse separadamente, tal como haremos a continuación.

En primer lugar, la pulsión de la exteriorización es la tendencia natural de un individuo a expresar por medio de gestos corporales un estado psíquico interno. Los ejemplos predilectos de Lipps son la expresión corporal de emociones tales como la ira, la afabilidad y la tristeza. Cada vez que vivenciamos uno de estos estados, nace en nosotros un impulso ciego a querer exteriorizarlo por medio de un gesto. Sin embargo, no siempre esta inclinación llega a término, es decir, a veces no se traduce en un gesto efectivo. Generalmente sucede, advierte Lipps, que "contra-tendencias" o "inhibiciones" impiden la expresión de la emoción en un momento dado. A modo de ilustración, puede ocurrir que en cierta situación yo padezca un estado emocional de cólera, pero la necesidad de mantener el recato (esto es, una contra-tendencia) impida que la emoción se

\footnotetext{
${ }^{19}$ Lipps, T., "Das Wissen von Fremden Ichen", en: Psychologische Untersuchungen, v. I, 4 (1907), pp. 694-722, p. 713 .

${ }^{20}$ En este trabajo dejamos de lado el tratamiento de la empatía en los dominios de la estética y la filosofia del arte realizado por Lipps, como así también por Friedrich T. Vischer, Johannes Volket y Wilhelm Worringer.

${ }_{21}$ Ibid., pp. 717-718.
} 
exprese por medio de gestos corporales externos. Según Lipps, el vínculo que hay entre un gesto y una emoción no es de la índole causa-efecto. Se trata más bien de una especie de invocación: la emoción llama a la existencia (ins Dasein ruft) al gesto o también yace (liegt) en él. Asimismo, ambos hechos, el psíquico y el kinestésico, son captados por el sujeto conjunta e inmediatamente como una unidad. Dentro de la conciencia se dan como dos caras de una misma actividad indivisible e inmediata.

En segundo lugar, existe en nosotros un instinto de imitación de las acciones corporales y las expresiones faciales de otra persona en el momento en que las percibimos. Según Lipps, el ejemplo más claro es el bostezo y su alto indice de contagio. De manera involuntaria e irreflexiva reproducimos miméticamente las acciones corporales ajenas debido a una tendencia a generar mediante sensaciones kinestésicas un comportamiento corporal similar al observado. Si mayormente la observación de conductas corporales en los otros no desemboca en una imitación corporal y exterior del gesto es porque, como se vio también para el impulso de exteriorización, contra-tendencias inhiben su desenvolvimiento inicial y restringen la imitación al ámbito interno de la conciencia. Lipps supone que la imitación siempre se lleva a cabo, por lo menos en el recinto privado de nuestras mentes cuando no se transcribe a una modificación de mi cuerpo y su comportamiento.

Finalmente, el conocimiento de la vida mental de los otros se da en el entrelazamiento de las tendencias de imitación y expresión. Al percibir, por ejemplo, una persona con un rostro fruncido y enrojecido que da golpes fuertes sobre una mesa, imito por instinto, aunque sea internamente en mi conciencia, sensaciones kinestésicas análogas, y gracias a ellas se da inmediatamente en mí la vivencia de la emoción de ira como contraparte del fenómeno de expresión. Esta es la empatía, a saber, la experiencia de la unidad entre la percepción de un gesto ajeno, la sensación de un movimiento kinestésico por imitación y la vivencia de una emoción expresada a través del acto corporal mimético. Nótese que la empatía así descrita es una experiencia exclusivamente perceptiva, donde el yo capta por percepción externa un cuerpo ajeno y por percepción interna sensaciones, sentimientos y emociones intimas. No hay nada mentado de manera vacía, en términos husserlianos. Por eso, Lipps concluye de lo anterior que "los yo ajenos son el resultado de una pluralización instintiva de mí mismo, desencadenada por percepciones sensibles precisas"22.

${ }^{22}$ Lipps, T., Leitfaden der Psychologie, Leipzig: Engelmann, 1909, p. 35. 


\subsection{Critica a la teoría de la empatia como instinto de imitación y expresión}

Poco tiempo después de su presentación al público universitario, la teoría lippsiana de la empatía fue duramente criticada por miembros del campo fenomenológico. Max Scheler primero en Zur Phänomenologie und Theorie der Sympathiegefühle und von Liebe und Hass (1913), Edith Stein luego en Zum Problem der Einfühlung (1917) y, años más tarde, Aron Gurwitsch en su tesis de habilitación Die mitmenschlichen Begegnungen in der Milieuwelt (1931) atacan esta concepción de la imitación instintiva. Husserl, en cambio, mantuvo sus reservas contra ella por fuera de su obra publicada en vida. Debemos recurrir a textos póstumos de 1905-1913 si aspiramos a conocerlas. En los apuntes de esos años, es posible identificar tres puntos centrales de discrepancia del padre de la fenomenología con las ideas de Lipps sobre el conocimiento de la vida psíquica ajena. En pocas palabras, Husserl imputa al catedrático de Múnich los errores de: (1) confundir la empatía con un acto de percepción interna intuitivo, cuando en realidad se trata de una apercepción experiencial de un sujeto trascendente; (2) ostentar una "ignorancia fenomenológica"23 por detener el análisis de la empatía en "instintos inexplicables" que no alcanzan a exponer las capas constitutivas más profundas y originarias de la alteridad subjetiva $^{24}$; (3) reducir el tratamiento de la aprehensión de la subjetividad ajena a la cuestión de la expresión, pasando por alto así niveles más básicos y originarios de la comprensión de la alteridad, como la constitución trascendental de un cuerpo físico externo en cuanto que cuerpo vivo. Veamos a continuación más en detalle estas tres denuncias.

En uno de los textos más antiguos conservados sobre la empatía, establecido alrededor de 1916 sobre la base de algunas notas escritas antes de 1909, Husserl afirma: "Lipps combate la teoría del razonamiento por analogía, pero desde un análisis más amplio, combate de igual modo la teoría de la apercepción en tanto que apercepción experiencial (Erfahrungsapperzeption)"25.

En efecto, hemos expuesto más arriba que, según Lipps, la empatía es enteramente un acto intuitivo en sus dos facetas: por una parte, la percepción de un cuerpo ajeno; por otra, las sensaciones kinestésicas propias producto del instinto de imitación. La vida psíquica de otro sujeto es por principio inaccesible por vía directa e intuitiva. "[Y]o solo me conozco a mí mismo de manera

${ }^{23}$ Cf. Hua XIII, p. 24.

${ }^{24}$ Stein dirá en sintonía con Husserl que reducir la empatía a meros instintos conduce a "la bancarrota de la investigación científica" (Stein, E., Sobre el problema de la empatía, p. 55).

${ }^{25}$ Hua XIII, p. 23. 
directa"26, afirma el pensador pionero de la Einfühlung. Esto significa que yo únicamente tengo acceso a mis propias vivencias y jamás puedo contemplar el interior de la mente ajena. Por este motivo, Lipps considera que la empatía implica exclusivamente una percepción de sí, una experiencia de las actividades del yo exclusivamente. Aclarado esto, el mecanismo del conocimiento de los otros se describe en los siguientes términos: "[En los procesos empáticos] el objeto de la percepción sensorial se extrae del mundo exterior, la excitación interna, contrariamente, se origina de la única fuente de la cual puede originarse, yo mismo. Según su origen, no es otra cosa que un modo de mi propia actividad" 27 .

Ahora bien, Husserl considera que el acto que nos permite conocer la conciencia de los otros no es de ningún modo una percepción que presenta el objeto de manera intuitiva y original, ni mucho menos una autopercepción de sí mismo, sino que se trata más bien de un tipo de apercepción particular que acompaña a la percepción del cuerpo ajeno y que intenciona al yo psíquico en una co-presentación, una co-percepción o una a-presentación ${ }^{28}$. Se trata entonces de una presentificación (Vergegenwärtigung). En la empatía, el objeto no es dado de manera original, al contrario del caso de una percepción de una emoción interna. Evidentemente, la experiencia de un dolor ajeno es por naturaleza distinta a la experiencia de un dolor propio. Este último nos presenta al objeto, según la expresión husserliana, en carne y hueso (leibhaft), es decir, en su presencia originaria. En cambio, el dolor ajeno es una a-presencia, está mentado de un modo vacío (esto es, no intuitivo u originario). Entra en juego aquí la diferencia entre presentación (Präsentation) y apresentación (Appräsentation), correspondiente a la dupla terminológica de percepción (Perzeption) y apercepción (Apperzeption).

Sin embargo, al igual que un acto perceptivo, la apercepción de la empatía capta su objeto de manera directa, esto es, sin intermediarios (imágenes, signos, inferencias lógicas mediatas). En el segundo libro póstumo de Ideas, Husserl es muy claro al respecto: "Si nos vemos uno a otro a los ojos, entonces sujeto y sujeto entran en un contacto inmediato... La mediatez de la expresión no es

${ }^{26}$ Lipps, T., "Das Wissen von Fremden Ichen”, p. 694.

27 Ibid., p. 714.

28 En estos años Husserl, para nombrar el acto singular de la aprehensión de la psiquis ajena, utiliza un conjunto de términos que abarcan "Kompräsentation" (co-presentación), "Mitwahrnehmung" (co-percepción) y "Appräsentation" (a-presentación). El vocabulario aquí en juego da prueba de los esfuerzos de Husserl por demostrar que la Einfühlung no es un acceso original a las vivencias de los otros. Finalmente, a partir de un texto de 1916 aproximadamente (cf. Hua XIII, pp. 33-35), toma preferencia por el vocabulario de la Appräsenz (a-presencia). 
mediatez de una inferencia de experiencia. 'Vemos' al otro y no meramente el cuerpo del otro; él está para nosotros presente él mismo, 'en persona' (in eigener Person), no solo corporal, sino espiritualmente"29.

Vale aclarar que la inmediatez de la empatía no significa intuitividad. La conciencia de otro sujeto, si bien pueden serme dada in eigener Person (es decir, sin intermediarios), no se me aparecen leibhaft (en el modo de la presencia). Aquello que se me revela con plenitud intuitiva -aunque en horizontes potenciales- es el cuerpo extraño del otro, y este es interpretado aperceptivamente como componente de una unidad psicofísica que forma junto con un yo psíquico. En toda apercepción la conciencia va más allá de lo dado sensorialmente e intenciona un excedente no-intuitivo, que se encuentra ausente o latente: en el caso de la empatía, se trata de la persona psíquica y la conciencia trascendental ajenas.

Asimismo, claramente contra Lipps, Husserl sostendrá en un escrito de febrero de 1927 que el objeto de la empatía "no es una reduplicación de mi yo, dotado de mi esfera original concreta, del cual tengo experiencia interpretándolo en cuanto otro"30. Lipps sugeria que el otro sujeto no es otra cosa que una proyección -entiéndase aquí duplicación- hacia un cuerpo externo de estados internos de mi propio ego ocasionados por las tendencias instintivas de imitación y expresión. El fenomenólogo, al contrario, insiste en que la empatía capta directamente por medio de presentificaciones las vivencias del otro a título de objetos trascendentes, y no inmanentes como sostiene Lipps ${ }^{31}$. Esta consideración llevó a Husserl en un texto temprano de 1914/5 a decir que el término "empatía" (Einfühlung) es inadecuado para describir nuestro acceso a la conciencia del otro, puesto que "yo no puedo transpórtame hablando con propiedad dentro del otro, sino que puedo simplemente representarme lo que yo sentiría si fuese como el otro... Hablando con propiedad, ninguna empatía tiene lugar"32.

"Empatia" en esta cita referiría estrictamente a sentir -en el sentido más propio del término- las mismas experiencias psíquicas que está viviendo el otro. No obstante, la legitimidad del uso de la palabra "Einfühlung" será

\footnotetext{
29 Hua IV, p. 375.

30 Hua XIV, p. 525.

31 Edith Stein desarrolla y profundiza esta crítica en su estudio sobre la empatía de 1917. Según ella, Lipps ve en la empatía un acto intuitivo de percepción de sí porque no distingue entre actos diversos como el empatizar (einfühlen), el cosentir (mitfühlen) y el sentir a una (einsfühlen). Cf. Stein, E., Sobre el problema de la empatia, pp. 28-35.

${ }^{32}$ Hua XIII, p. 338. Las cursivas son nuestras.
} 
eventualmente justificada por la participación de la imaginación en el proceso empático, al nivel de la empatía auténtica que desarrollaremos más adelante, puesto que esta permite tener una experiencia presentificativa de las vivencias del otro "como si" yo estuviese en su lugar.

Así pues, para Husserl, la empatía es una apercepción de un objeto trascendente, puesto que la vida psíquica del otro no se da intuitiva y originalmente, ni se halla dentro de lo que Husserl llamará más tarde, en los comienzos de su período genético a partir de 1920, la esfera de "la realidad solipsista", "de la experiencia original", "de la experiencia primordial" o "de lo mío propio". Lipps cometió entonces el error de no distinguir entre una conciencia perceptiva de sí y una conciencia aperceptiva del otro, entre una vivencia original y otra no original.

Esta falta está estrechamente vinculada al segundo gran problema de su teoría, a saber, la creencia de que la empatía es meramente el resultado de instintos naturales. Al respecto, Husserl asevera con crudeza: "Desde un punto de vista fenomenológico, los 'instintos inexplicables' son un refugio para la ignorancia fenomenológica, pues la 'explicación' que aquí importa es la elucidación que toma a la verificación (Ausweisung) como hilo conductor"33.

Dicho de otro modo, en la medida que se comprende la empatía como un juego de instintos irreflexivos y automáticos, no es posible explicar el hecho evidente de que esta implica un decurso temporal de una multiplicidad de experiencias que el sujeto tiene sobre el mismo objeto, las cuales pueden confirmar, modificar o anular el sentido y las tesis del objeto puestos por el acto primigenio. En su cualidad de apercepción, la empatía intenciona una faceta del objeto de forma vacía y al mismo tiempo apunta (abzielen) hacia la plenificación o cumplimiento (Erfüllung) de la misma. No obstante, el acto que intenciona una alteridad subjetiva está inhabilitado a acceder a una verificación auténtica: "yo no puedo efectivamente recibir la intuición de ninguna de las apariciones presentificadas del sujeto del cuerpo vivo y de sus sensaciones, de sus movimientos, de sus propiedades psíquicas, y esto es así por principio"34. Por este motivo, la empatía tiende hacia una confirmación de orden especial. Se trata originariamente de la adecuación entre, por un lado, el horizonte vacío de anticipaciones que establece la transferencia aperceptiva del sentido de cuerpo vivo propio al cuerpo físico de otro y, por otro, la percepción externa del comportamiento ulterior de ese cuerpo extraño.

\footnotetext{
${ }^{33}$ Ibid., p. 24.

${ }^{34}$ Ibid., p. 317.
}

ARETÉ Revista de Filosofía, vol. XXXI, N² 2, 2019 / ISSN 1016-913X 
Considérese lo que afirma Husserl: "[E]1 cuerpo vivo ajeno objeto de experiencia se atestigua continuamente como cuerpo vivo real tan solo en su cambiante pero siempre acorde 'conducta', de tal modo que ésta tiene su lado físico que es índice apresentativo de lo psíquico; lo cual tiene que aparecer impletivamente en experiencia originaria. Y así en el perpetuo cambio de la conducta de fase a fase. El cuerpo vivo se experimenta como cuerpo ilusorio justo cuando no va acorde con ello"35. Por consecuencia, la explicación por la combinación de los instintos de imitación y expresión de Lipps pierde de vista el fenómeno de la verificación de la empatía, que, para Husserl, debe ser el hilo conductor de la investigación. La empatía goza de un proceso de constitución y confirmación que es necesario explicitar científicamente, a partir de una fenomenología que practique antes que nada la reducción, con el fin de evitar caer en supuestos naturalistas y psicológicos tales como los instintos.

Privado de la brújula apropiada, la teoría lippsiana cae en un tercer y último equívoco expuesto en la siguiente cita: "Lipps está completamente obnubilado por el problema de la expresión de las expresiones psíquicas ${ }^{36}$, y ciego al hecho de que la percepción del otro presupone primariamente la comprensión del cuerpo vivo como cuerpo vivo, y esto sucede antes de cualquier relación entre el cuerpo vivo y el sujeto en el sentido del sujeto espiritual" ${ }^{37}$.

Es menester advertir que la expresión para Husserl no es la mera reacción instintiva, fisiológica y causal a partir de estados psíquicos internos. Al contrario, corresponde a la aprehensión de una conexión de motivación entre, por una parte, sentimientos, emociones, valores y carácter de la personalidad de un sujeto y, por otra, intenciones prácticas, actos de voluntad y acciones. Esta aprehensión es un acto de comprensión íntima de la expresión que involucra a la persona entendida como sujeto psíquico y espiritual. La constitución de la persona humana está, de hecho, fundada sobre estratos constitutivos más originales según el orden de la fundamentación trascendental de la experiencia. En

\footnotetext{
${ }^{35}$ Husserl, E. Meditaciones cartesianas, Gaos, J. y M. García-Baró (trads.), México D.F.: FCE, 2005, pp. 62-63.

${ }^{36}$ Exactamente el mismo problema es destacado y criticado por Stein en la página 55 de su tesis doctoral: "[Lipps] está como cautivado por el fenómeno de la expresión de las vivencias y vuelve una y otra vez a ello parta de donde sea. El cúmulo de cuestiones que hay antes del tratamiento de este problema... lo despacha en dos palabras: en virtud de una 'disposición inexplicable de nuestro espíritu' o de un 'instinto natural' pensamos en una vida consciente ligada a ciertos cuerpos físicos. Esto no significa otra cosa que la proclamación del milagro, la declaración de la bancarrota de la investigación científica". Esta cita demuestra la estrecha colaboración entre Husserl y Stein respecto del estudio de la empatía.

37 Ms. E I 3 II, p. 161 a , texto citado por el editor Kern en la nota $n^{\circ} 2$ de Hua XIII, p. 74.
} 
primer lugar, es necesaria una representación del otro como unidad psicofísica entre un cuerpo y un alma, y de esta unidad puede abstraerse un estrato más fundamental, de hecho, el más originario de todos, que es la de la corporalidad viva o propia (Leiblichkeit). Esta está compuesta por la capa estesiológica de sensaciones sensibles, sensaciones kinestésicas y sensaciones localizadas.

El análisis de Lipps no supo ver los fundamentos subyacentes y primordiales que habilitan el fenómeno de la comprensión de una expresión subjetiva ajena. Por eso, Husserl sostiene: “Si imaginamos una 'percepción' primera (originalmente instauradora) de otro, la primera cosa es entonces manifiestamente la interpretación fundadora, la de la corporalidad externa (Aussenkörperlichkeit) allí en cuanto que corporalidad viva (Leiblichkeit), presentificada en la orientación-cero y en cuanto que cero de un mundo orientado que es identificado con el mundo del cual hago la experiencia original" 38 .

Así pues, según Husserl, antes de la expresión está la captación del otro en tanto que cuerpo vivo. Tal como afirma Natalie Depraz en su introducción a la traducción francesa de los tomos de Husserliana sobre la intersubjetividad, Husserl comprende entre 1905 y 1910 la Einfühlung como reveladora de una esfera ante-expresiva estesiológica, la esfera de las sensaciones ${ }^{39}$. Esta comprensión conduce al análisis fenomenológico de la donación del cuerpo vivo propio, pre-dado a mí mismo antes que cualquier otro cuerpo ${ }^{40}$.

Mi cuerpo tiene un modo de aparecer privilegiado y radicalmente distinto al de cualquier otro objeto del mundo. De él poseo una experiencia ambigua que Husserl denomina, en un texto de sus vacaciones en la Selva Negra de 1921, "fantasmática"41, puesto que en ella se fusionan y confunden una percepción somática o interna y una percepción física o externa del mismo. Por un lado, la percepción física del cuerpo lo muestra como una cosa entre otras del espacio físico, sumergida en el universo causal de relaciones mecánicas entre los objetos extensos y materiales. Por el otro, la somática exhibe al cuerpo como soporte de sensaciones y movimientos localizados, receptáculo sensible y estructurado de los data sensoriales y los data kinestéticos. Asimismo, lo da en calidad de

\footnotetext{
38 Hua XIV, p. 526.

39 Depraz, N., "Introduction", en: Husserl, E., Sur l'intersubjectivité, Depraz, N. (trad.), París: PUF, v. I, 2001, p. 27.

40 “La apercepción 'mi cuerpo vivo' es de manera originalmente esencial la primera, y es la única que debe ser enteramente original... [La apercepción de un cuerpo vivo ajeno] exige que yo me haya dado anteriormente mi cuerpo vivo en una apercepción. Cada cuerpo vivo se refiere entonces a mi cuerpo vivo a su vez" (Hua XIV, p. 7).

41 Cf. ibid., p. 57.
} 
centro fijo de orientación de las posiciones y las distancias de los objetos del universo físico, es decir, mi cuerpo es el punto cero de todas las dimensiones espaciales. Por último, mi corporalidad se revela también como un sistema de órganos sujeto a mi voluntad, del cual tengo un poder directo e inmediato y a partir del cual puedo actuar libremente en el mundo externo y modificar los sistemas de aparición posibles de las demás cosas mundanas.

Cabe mencionar que, para Husserl, la percepción somática del cuerpo es anterior a aquella que nos lo ofrece como objeto físico ${ }^{42}$ y que, solo luego de la constitución intersubjetiva de un mundo objetivo por medio de la empatía, el cuerpo deviene por completo cosa física"3, una "cosa espacial como todas las demás... el objeto de la naturaleza 'hombre' (ser animal"44. Previamente, según el orden de fundamentación, en el marco de la experiencia llamada solipsista, mi cuerpo es solo "una cosa constituida de modo curiosamente imperfecto" 45.

De regreso a la crítica contra Lipps, el fenómeno de la expresión no es ni la única ni la primera cuestión del análisis de la empatía entendida como modo de aprehensión de un yo ajeno. Antes que nada, se encuentra la apercepción de un cuerpo extraño en cuanto que cuerpo vivo similar al mío. La obsesión del primer teórico de la Einfühlung por el tema de la expresión no le permitió ver esta primera evidencia fenoménica.

\section{El enfoque genético en la teoría de la empatia}

Hasta aquí hemos visto que, entre 1905 y 1920 aproximadamente, Husserl comprende la empatía como una apercepción experiencial de un yo psíquico ajeno a partir de la percepción de un cuerpo fisico, interpretado este último en términos de un cuerpo vivo similar al mío. Esta comprensión se formó en paralelo a la refutación de teorias rivales acerca del conocimiento de los otros, en particular la teoria de la inferencia por analogía de Erdmann y la de la empatía como imitación instintiva de Lipps. Así fueron los primeros pasos de la construcción de una teoría fenomenológica de la intersubjetividad por parte de Husserl. La etapa siguiente de esta elaboración está marcada por el nacimiento de una fenomenología genética alrededor de $1918^{46}$ y por el descubrimiento

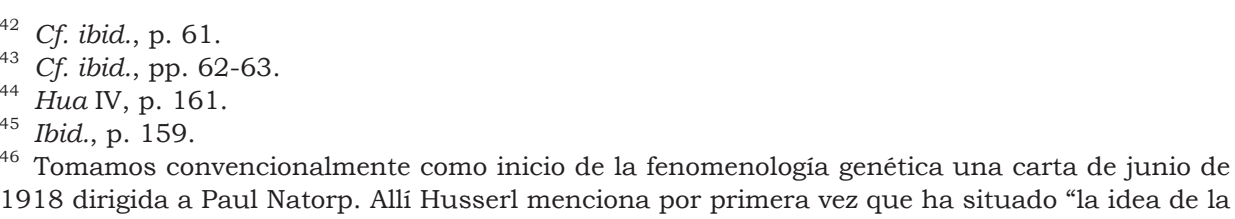


de sintesis pasivas que anteceden y condicionan la actividad cogitativa del yo. Si bien la nueva perspectiva genética acerca de la empatía podrá parecer en una primera lectura alejada de las teorias de Erdmann/Mill y Lipps, recupera, no obstante, cierta idea original propia de cada una de ellas. En concreto, un proceso de analogización (Mill/Erdmann) vuelve a ocupar el primer plano en el conocimiento del otro, aunque esta vez no bajo el modo de una inferencia, sino bajo el modo de una asociación parificadora en el marco de la percepción del cuerpo ajeno. A su vez, la parificación demuestra que la pre-donación del otro no es de ninguna manera un acto explícito de un yo atento y despierto (Lipps), sino que es primariamente una síntesis pasiva anterior y condicionante de las vivencias del tipo ego cogito cogitatum.

\subsection{Fenomenología genética, las sintesis pasivas y la empatía inauténtica}

La fenomenología genética es un análisis de la historia de la autoconstitución de la conciencia y de sus correlatos a lo largo del tiempo subjetivo. Describe la formación de la vida trascendental según un "nexo de condicionamiento entre motivante y motivado" 47 de las vivencias del flujo temporal de la conciencia. Este nexo se construye a partir de leyes trascendentales genéticas ${ }^{48}$ que rigen los distintos tipos de sintesis pasivas. Del conjunto de estas sintesis que conforman la legalidad pasiva-genética podemos destacar las siguientes, respetando el orden de fundamentación de la experiencia consciente: las sintesis formales del tiempo (retención, impresión, protensión), los instintos teleológicos de la historia generativa trascendental, las sintesis asociativas (protoasociación, asociación reproductiva y asociación inductiva de los datos hyléticos pre-objetivos) y las habitualidades de un yo monádico ${ }^{49}$. Todas estas sintesis preconfiguran subterráneamente los actos conscientes y objetivantes del yo despierto y atento.

Por supuesto, en lo que respecta a nuestro tema, debemos incluir en la lista de sintesis pasiva lo que Husserl denomina "empatía inauténtica" o "impropia" (uneigentliche Einfühlung). Esta consiste en la aprehensión más original, básica y pobre que se puede tener de otra subjetividad, tanto animal

\footnotetext{
génesis trascendental como el tema principal en fenomenologia" (Husserl, E., Briefwechsel. Band V. Die Neukantianer, Boston: Kluwer, 1994, p. 137).

47 Hua XIV, p. 41.

48 Cf. Hua XI, p. 342.

49 Para un tratamiento completo y exhaustivo de esta lista, véase: Osswald, A.M., Fundamentación pasiva de la experiencia: Un estudio sobre la fenomenología de Edmund Husserl, Madrid: Plaza y Valdés, 2016.
} 
como humana. Más específicamente, la empatía inauténtica es una apercepción pasiva que constituye al otro a título de un alter ego pre-dado ${ }^{50}$, gracias a un proceso pasivo de emparejamiento o parificación (Paarung), esto es, una asociación perceptiva que enlaza analógicamente por sus semejanzas un cuerpo físico extraño con mi cuerpo vivo. Su inautenticidad se debe al hecho de que solamente me da al otro como referencia vacía e indeterminada de una corporalidad viviente (Leibkörperlichkeit). Se trata de un objeto que posee la particularidad de ser sujeto de sensaciones (externas, kinestésicas y localizadas) y presenta cierta movilidad autónoma a partir de un sistema de orientaciones propio.

Esta empatía primigenia, como toda apercepción, reclama su cumplimiento respectivo. Este radica en la realización de una empatía auténtica o propia (eigentliche Einfühlung), que hace uso de la imaginación para transportarse presentificativamente dentro del cuerpo ajeno. Así, yo imagino las vivencias internas del otro como si estuviese en su lugar ${ }^{51}$. Por medio de actos de la fantasía develo progresivamente la intimidad psíquica, e incluso la trascendentalidad egológica, de lo que anteriormente era un simple cuerpo viviente vacío e indeterminado. Con la empatía auténtica se da por fin la "donación del otro propiamente dicha" 52 y el término "Einfühlung" (esto es, un sentirse dentro de otro) cobra pleno sentido.

En una nota de un texto de junio de 1920, Husserl afirma: "La empatía inauténtica es la indicación asociativa, bajo un modo pasivo, de una subjetividad extraña; 'la empatía' dicha con propiedad es el co-hacer y el co-padecer con el otro, el hecho de dejarse motivar yóicamente, pero también, subterráneamente, el hecho de seguir más las motivaciones internas que las asociaciones" 53 .

Sin embargo, por esto no debe entenderse en absoluto que la empatía inauténtica es superada y abandonada, como si se tratase de una etapa transitoria. Al contrario, subyace por siempre bajo los nuevos actos motivados internamente en calidad de indispensable fundamento pasivo sobre el cual se constituyen las capas superiores de la aprehensión del otro (su vida psíquica y espiritual).

Así pues, el germen de la captación de una subjetividad distinta a la mía reside primariamente en la empatía inauténtica y el proceso de parificación que la constituye. Al respecto de la parificación, Husserl escribe en las

\footnotetext{
50 Cf. Hua XIII, p. 438.

51 Cf. Hua XV, p. 427.

52 Hua XIII, p. 439.

53 Ibid., p. 455.
} 
Meditaciones cartesianas: "Se trata de una forma originaria de síntesis pasiva que... designamos 'asociación'. En una asociación parificadora, lo característico es que, en el caso más primitivo, están dados, en la unidad de una conciencia, destacados intuitivamente, dos datos, y que, sobre la base de su aparecer como distintos... fundan fenomenológicamente una unidad de semejanza; esto es, que, justamente, están siempre constituidos como un par"54.

La parificación de cuerpos (Körper-Paarung) no solo implica la constitución del cuerpo físico del otro como cuerpo viviente sino también, inversamente, la fisicalización de mi corporalidad viviente más allá de los límites posibles de una experiencia solipsista. La reducción a la espera de lo mío propio, que abstrae del horizonte de experiencia todo lo que es ajeno, pone entre paréntesis la consideración de mi cuerpo y mi yo como cosas integradas en el mundo objetivo, el cual, para Husserl, es constituido de manera intersubjetiva. Es por medio de la empatía que el yo trascendental se aliena y logra alcanzar una representación (ajena) de sí mismo. Por eso, dice Husserl: "En el intercambio intersubjetivo de experiencias [el yo puro] se convierte en yo real objetivo [objetiven realen Ich]"55.

Al confirmar la naturaleza asociativa y pasiva de la parificación, el problema que se presenta a continuación es el de la definición de la asociación desde la fenomenología. Nos encontramos ante una noción tardía del pensamiento husserliano, que cuenta con un desarrollo acotado en las obras publicadas en vida del filósofo alemán. Es mencionada por primera vez en los §38-39 de Meditaciones cartesianas (1931). Allí se lee que la asociación es el principio universal de la génesis pasiva por encargarse de "la configuración sensible en la coexistencia y en la sucesión" 56 . Sin embargo, el tratamiento no avanza mucho más. Por otro lado, puede mencionarse, conservando ciertas reservas, el libro Experiencia y juicio (1938), publicado inmediatamente luego de la muerte del autor y editado por su colega Ludwig Landgrebe. En los parágrafos que van del 15 al 46, Husserl analiza la experiencia antepredicativa de carácter pasivo que funda los actos judicativos estudiados por la lógica. El análisis concluye que "los datos sensibles", es decir, el material hylético que es aprehendido e informado por el yo para constituir un objeto intencional, "son ya productos de una síntesis constitutiva, que en cuanto nivel más bajo presupone las operaciones de la síntesis de la conciencia interna del tiempo"57.

\footnotetext{
54 Husserl, E., Meditaciones cartesianas, pp. 160-161.

55 Hua XV, p. 114.

${ }^{56}$ Husserl, E., Meditaciones cartesianas, p. 120.

57 Husserl, E., Experiencia y juicio, p. 75.
} 
Estas sintesis que configuran el contenido material de los datos temporales inmanentes de la conciencia son las sintesis de asociación. Experiencia y juicio expone las leyes asociativas de semejanza/homogeneidad (Verwandtschaft/ Homogeneität) y extrañeza/contraste/heterogeneidad (Fremdheit/Kontrast/ Heterogeneität) que estructuran el material pre-objetivo sensible de lo percibido en la actualidad y lo evocado en el recuerdo. Asimismo, presenta el concepto fundamental de afección (Affektion), esto es, la tendencia que tienen ciertos contenidos pre-objetivos de destacar y lograr "llamar la atención" (aufallen) del yo, el cual responde dirigiéndose a ellos de manera aprehensiva y explícita.

Ahora bien, el tratamiento más amplio de la asociación reposa en escritos póstumos del corpus husserliano. Son de suma importancia los cuadernos de apuntes preparatorios de los cursos que Husserl impartió en la Universidad de Friburgo en el semestre de invierno de 1920/1921, en el semestre de verano de 1923 y nuevamente en el semestre de invierno de 1925/26. Los mismos fueron editados por Margot Fischer en el volumen XI de Husserliana: Analysen zur passiven Synthesis. Aus Vorlesungs- und Forschungsmanuskripten 19181926 y publicado en 1966. La división 3 de la parte II de este volumen lleva por título "Asociación" y se encarga de describir los mecanismos pasivos de la asociación reproductiva que evocan el pasado, de la asociación inductiva que predelinean el futuro y de la protoasociación que constituyen el campo sensible afectante del presente actual.

Nos detendremos un momento en la presentación de los dos primeros tipos de asociaciones, puesto que son los procesos asociativos genéricos que están a la base de la parificación de la empatía y su cumplimiento. Luego, intentaremos reconstruir lo que Husserl desarrolló muy escuetamente en el $\S 51$ de las "Meditación quinta", a saber, el funcionamiento asociativo de la parificación empática.

\subsection{Asociación reproductiva y asociación inductiva al interior de la parificación empática}

En primer lugar, la asociación reproductiva (reproduktive Assoziation) es el proceso que explica la motivación de un recuerdo, es decir, las razones de por qué en cierto momento nos vemos llevados a rememorar particularmente cierta escena, objeto, sensación o sentimiento de nuestro pasado. Esto se debe a una evocación o un despertar (Weckung) de un contenido pretérito que se destaca por su semejanza (Ähnlichkeit) con el contenido presente. Husserl habla de un fenómeno de "evocación retroirradiante" (rückwirkende Weckung) en el cual la 
fuerza afectiva de un elemento evocante de la protoimpresión se proyecta hacia cierta unidad retenida en el pasado y esta consigue ser reflejada hacia la esfera de lo actual. Así es como, cuando visito el hogar donde transcurrí mi infancia, surge la tendencia de recordar escenas de mi niñez en esa casa, puesto que, por ejemplo, la percepción actual de los muebles que perduraron a lo largo de los años evoca a la percepción que de ellos tuve cuando era un niño. La asociación puede ocurrir sin la percatación atenta del yo, es decir, sin alcanzar la fuerza afectiva necesaria para motivar un acto objetivante de rememoración y simplemente resaltar de manera vacía vivencias retencionadas del pasado. Por otra parte, esta asociación reproductiva, al igual que asociaciones de otros tipos, puede encadenar una serie de evocaciones mediatas, donde la experiencia presente de $a$ rememora a $b$, y a su vez $b$ nos hacer recordar a $c$, y así sucesivamente.

En segundo lugar, la asociación inductiva (induktive Assoziation) se encarga de anticipar la experiencia futura en virtud de la experiencia pasada y explica la génesis de los actos de espera del yo activo. Es necesario remarcar que este género de asociación está supeditado al de tipo reproductivo, dado que en la experiencia, según las palabras de Husserl, "se espera que el devenir ulterior sea análogo al devenir anterior"58. Es decir, cada vez que vuelvo de adulto a visitar mi casa materna, espero encontrarla tal cual la conservo en mi memoria, si es que no tuve noticias de ningún cambio en ella. Aquí nos enfrentamos a un proceso inductivo previo y a su vez fundante de la inducción inferencial perteneciente a la esfera de los juicios estudiados por la lógica. Cada nueva experiencia no es el advenimiento de algo por completo novedoso e inesperado. Al contrario, goza de un predelineamiento, de una formación anticipadora, que es el producto de una síntesis pasiva de asociación entre el pasado y el futuro.

Ahora bien, tanto la asociación reproductiva como la asociación inductiva se encuentran a la base del proceso de parificación entre un cuerpo ajeno y mi cuerpo propio en la empatía. Esta aseveración y su justificación subsiguiente deben ser comprendidas como una hipótesis interpretativa que pretende reconstruir los lazos teóricos del tratamiento de la asociación y el de la empatía en Husserl.

472 En el germen de la empatía primero sucede un fenómeno de evocación reproductiva. El cuerpo del otro con su apariencia y su comportamiento particulares sirven de factor evocante del modo de aparición externa de mi propio cuerpo guardado en mi memoria. Algo en mi campo de visión se parece a mí y actúa como yo. Ese objeto "me recuerda" a mí mismo, aunque acá no se trata

${ }^{58}$ Hua XI, p. 186. 
de una rememoración activa. El grado de semejanza entre ambos objetos, cuyo caso límite es la perfecta identidad, es aquello que regula el poder afectante que la experiencia perceptiva del cuerpo ajeno transfiere a la retención de mi experiencia corporal pasada para que sea rememorada y traída a la conciencia. Sin embargo, en el caso de la empatía, no solo acontece una transferencia afectiva de la evocación que va de la percepción del cuerpo extraño hacia el recuerdo del mío, sino también sucede una transferencia del sentido de cuerpo vivo en dirección inversa a la anterior. Este fenómeno tiene el nombre de "solapamiento" o "cubrimiento" (Deckung). En efecto, ese objeto de allí que grita si se lastima, que se mueve con vistas a un fin, etcétera, debe ser un cuerpo sintiente y animado por una voluntad similar al mío. Entonces, el elemento evocante, el cuerpo extraño, se cubre del mismo sentido del elemento evocado: a saber, la cualidad de ser, además de un objeto fisico, un cuerpo viviente. Por eso, Husserl afirma que "cada cuerpo vivo se refiere entonces a su vez a mi cuerpo vivo" 59 , el único del cual puedo tener una apercepción por completo original.

El solapamiento de sentido entre evocante y evocado abre de inmediato una esfera de anticipaciones pasivas, con el fin de mantener la adecuación de la interpretación del cuerpo extraño del otro como cuerpo viviente. Yo "espero" que el cuerpo del otro continúe teniendo de manera coherente un comportamiento de cuerpo vivo análogo al mío -aunque aquí, nuevamente aclaramos, no se trata de una espera activa-. Entran, pues, en escena las operaciones propias de la asociación inductiva aplicadas a la captación de una subjetividad corporal extraña. Así, se configura una serie de intenciones vacias anticipadoras que exigen ser verificadas para mantener el sentido y la tesis del objeto de la empatía.

En resumen, el funcionamiento de las sintesis pasivas de reproducción e inducción explicado en las notas de preparación de los cursos en Friburgo en la década de 1920 permite comprender mejor el fenómeno de la parificación en la experiencia de la semejanza de un cuerpo externo con mi cuerpo propio. El parecido entre el cuerpo del otro y el mío según el modo de darse de la corporalidad externa (Korperlichkeit) desencadena un despertar o evocación de las experiencias fantasmáticas retenidas de mi cuerpo, incluidas las vivencias de mi corporalidad viviente (Leiblichkeit). Luego, "un recubrimiento interviene paso a paso con la evocación asociativa: lo percibido porta progresivamente en él 'la imagen del recuerdo' de aquello que se evoca" ${ }^{\circ}$. El cuerpo ajeno se recubre del

59 Hua XIV, p. 7.

60 Hua XIV, p. 529. 
sentido de cuerpo viviente, con su respectiva capa estesiológica, su sistema de orientación y su carácter de ser animado por un yo que en estas instancias es indeterminado. Se abre así una serie de múltiples anticipaciones asociativas que esperan del otro que se siga comportando como un cuerpo propio análogo al mío. Estas expectativas pasivas son el umbral de la empatía inauténtica. Un desarrollo ulterior del sentido del otro requerirá la asistencia de la imaginación en una intervención activa de mi yo atento.

\section{El legado de Erdmann y Lipps en la teoria de la empatia husserliana}

La anterior exposición de la génesis pasiva del otro, es decir, de la empatía inauténtica como vivencia primordial y fundadora de la alteridad subjetiva, nos abre el camino para indagar el destino de las teorías de la inferencia por analogía de Erdmann/Mill y de la imitación instintiva de Lipps en la filosofia husserliana. Habiendo visto en la primera sección de este artículo cómo Husserl rechazó ambas concepciones -una por suponer que el conocimiento del otro se da por una inferencia lógica, la otra por entender la empatía como un acto intuitivo fundado en instintos inexplicables- cabe ahora preguntarse si no queda algo más allá de estas impugnaciones. Ciertamente, es posible identificar algunas ideas o intuiciones originales de ambas doctrinas que fueron conservadas en las reflexiones fenomenológicas sobre la conciencia de la Einfühlung.

Primeramente, con respecto a la teoría Erdmann/Mill, Husserl coincide en otorgar un papel relevante e imprescindible a la analogía en el curso del conocimiento de otros sujetos. La analogía es esencialmente la asociación en el dominio de la percepción de rasgos sensibles físicos y conductuales externos del cuerpo del otro y del mío según sus semejanzas y similitudes. Este proceso analógico, ya sea producto de una asociación pasiva, ya sea parte de una inferencia lógica, es una condición sine qua non para que se dé tanto un acceso cognitivo a la mente de otro individuo como la constitución del sentido de la otredad subjetiva. Si el cuerpo que tengo en frente no se parece en nada a mí mismo (por ejemplo, un cuerpo que no tiene órganos sensoriales, que no se mueve, que no se alimenta, y así hasta los umbrales la vida biológica), jamás podrá ser interpretado como soporte de una entidad psíquica ${ }^{61}$. Sin duda, en este punto están de acuerdo Mill, Erdmann y Husserl.

\footnotetext{
61 Aquí está mencionado el tema de la empatía de sujetos no humanos o de los confines del alcance de la empatía. Esta cuestión está presentada, por ejemplo, en el tomo II de Ideas, donde Husserl elabora la idea de que los animales también son aprehendidos empáticamente como subjetividades yoicas en razón de su semejanza a nivel somático con los seres humanos y, en
} 
El problema principal que el fenomenólogo denuncia de la teoría de sus contrincantes no concierne a la función de la analogía, sino al desconocimiento de que la analogía es originariamente una percepción experiencial, anterior a cualquier razonamiento lógico e independiente de él. Esta tesis forma parte del espíritu fundacional de la fenomenológica husserliana, plasmado tempranamente en la introducción de la primera edición de las Investigaciones lógicas (1900-1901). Allí, Husserl afirma categóricamente: "Los conceptos lógicos, como unidades válidas del pensamiento, tienen que tener su origen en la intuición"62. El estudio de las esencias puras de los actos lógicos emprendido en las Investigaciones desde una fenomenología estática da como resultado el descubrimiento de vivencias intuitivas que están a la base de los razonamientos de orden lógico. En el caso que aquí incumbe, el uso de argumentos inferenciales para deducir tal o cual estado mental en otro individuo es obviamente factible en algunos casos particulares, pero siempre supone una pre-donación del sentido de otro sujeto, aprehendido por una conciencia aperceptiva originaria que acompaña a la percepción de un cuerpo extraño. Además, los descubrimientos de la fenomenología genética enseñan que esta apercepción pone en funcionamiento una serie de operaciones pasivas (parificación, asociación reproductiva, asociación inductiva) que no involucran a un yo en cuanto que operador atento y activo de inferencias lógicas. Los orígenes de la vida intersubjetiva, es decir, la respuesta a la pregunta genética que, según Stein, los defensores de la teoría de la inferencia por analogía olvidaron formular, yace en una apercepción experiencial anterior e independiente a cualquier razonamiento lógico.

En segundo lugar, en lo que concierne a la visión de Lipps sobre la empatía, es dificil olvidar las punzantes palabras que Husserl utilizó en 1909 para referirse al recurso que Lipps hace de las tendencias instintivas de imitación y expresión en la formulación de la empatía: no son más que, recordemos, un "refugio de la ignorancia fenomenológica". A pesar de que nos desviará momentáneamente de nuestro interés actual, este es el momento de aclarar que en años posteriores la consideración de Husserl sobre la existencia de instintos en la esfera de la intersubjetividad, además de otros campos, cambia radicalmente. En un texto de 1933, es posible leer la sorprendente afirmación de que

\footnotetext{
última instancia, con mi yo psicofísico. El animal es definido, pues, como una variación de la normalidad representada y constituida por el ser humano y el yo personal. Cf. Osswald, A.M., Fundamentación pasiva de la experiencia: Un estudio sobre la fenomenología de Edmund Husserl, "Sujeto y pasividad", Sección 5.3: "El sujeto animal".

${ }^{62}$ Husserl, E., Investigaciones lógicas, García Morente, M. y J. Gaos (trads.), Madrid: Alianza Editorial, v. I, 2006, p. 218.
} 
"la primordialidad es un sistema de instintos (Triebsystem)"63. Esto significa que el origen último de la conciencia y de la constitución del mundo tiene lugar en una esfera de protointencionalidades ${ }^{64}$ (UriIntentionalitäten) regida por un sistema de tendencias, impulsos o instintos. Se trata del nivel trascendental del pre-yo (Vor-Ich) y de la hyle primera. En el marco de una fenomenología generativa y teleológica concerniente al estudio del orden racional que guía el desarrollo trascendental de la vida de una mónada, Husserl considera la existencia de una "protoempatía" (Ureinfühlung) perteneciente al orden pre-egológico de los impulsos o instintos que configuran un proto-horizonte universal, bagaje de habitualidades innatas de toda subjetividad absoluta65. Antes de que un sujeto adquiera una conciencia diferenciada de sí mismo, y previo a cualquier apercepción empatizante de un otro concreto y su cuerpo, existe una referencialidad instintiva no-objetivante a un proto-horizonte intersubjetivo. Esta se atestigua en la temprana relación madre-hijo ${ }^{66}$ y el impulso intersubjetivo (intersubjektiver Trieb) del apetito sexual67.

Estos temas de los años '30 forman parte de una nueva valorización de la función de los instintos en la vida consciente. Sin embargo, no están directamente ligados a nuestra pregunta, que residia en saber qué es lo que Husserl ha conservado de la teoría de la empatía lippsiana. La originalidad de la teoria de Lipps que puede hallarse de inmediato en las reflexiones husserlianas sobre la intersubjetividad es el reparo de la empatía como una operación de la conciencia distinta a un acto cogitativo o, dicho de otro modo, diferente a una actividad voluntaria y atenta de un yo. Los instintos o tendencias (Triebe) lippsianas son procesos automáticos que no requieren de la asistencia, la disposición o el consentimiento del sujeto entendido en términos de agente de todo acto de conciencia. Suceden, en términos de Husserl, de manera pasiva. Por lo tanto, a partir de los análisis de las síntesis pasivas y del fenómeno de parificación en la aprehensión de otro sujeto, hay un acercamiento en el pensamiento de los dos colegas alemanes respecto de la comprensión de la empatía como una operación que se origina por debajo del radar del yo, de los actos voluntarios y las actividades cognitivas racionales. Esta aproximación

\footnotetext{
63 Hua XV, p. 594.

64 Término que aparece en la sección "Fenomenología de la protointencionalidad" (fenomenología de los 'instintos') del "Plan para 'el sistema de filosofia fenomenológica' de Edmund Husserl", que Fink redactó y presentó a Husserl en el año 1940. Cf. ibid., p. xxxix.

${ }^{65}$ Para un tratamiento más específico de la temática, véase Walton, R., "Instintos, generatividad y tensión en la fenomenología de Husserl”, en: Naturaleza humana, v. IV, 2 (2002), pp. 253-292.

66 Cf. Hua XV, texto ${ }^{\circ} 33$, pp. 580-588 y Apéndice XLV, pp. 604-605.

${ }^{67}$ Cf. ibid., texto $\mathrm{n}^{\circ} 34$, pp. 593-597.
} 
quizás pueda argumentarse que se profundizará con los estudios generativos y teleológicos del fenomenólogo, pero ya se encuentra presente desde 1920 con la fenomenología abocada a la empatía.

\section{Conclusión}

Hemos elucidado con éxito en este artículo, a partir de la lectura y la interpretación de los textos póstumos editados por Kern en 1973 acerca de la intersubjetividad, dos de los hitos más relevantes en la construcción de la teoría de la empatía de Husserl, y hemos además dilucidado la conexión que guardan entre ambos. El primero de estos hitos fueron las críticas del fundador de la fenomenología entre 1905 y 1910 contra las principales teorias rivales que pretendian explicar nuestro acceso cognitivo a otros sujetos. Primero, expusimos claramente las tesis de Erdmann/Mill sobre una inferencia de cuatro pasos que deduce de la similitud entre conductas corporales, estados mentales internos en la mente de otro sujeto. Este razonamiento fue impugnado como falaz por sostenerse sobre una petición de principios y no comprender la naturaleza experiencial -es decir, antepredicativa- de la aprehensión de la psiquis ajena. Luego, pasamos revista a la concepción lippsiana de la Einfühlung: un hecho (Tatsache) instintivo que combina las tendencias de imitación y expresión durante la percepción del cuerpo de otro sujeto. Esta teoría también resultó insostenible para Husserl, puesto que obviaba la naturaleza aperceptiva de la experiencia empática, limitaba el fenómeno de la alteridad a la esfera de la expresión y estaba fundada acientificamente en el presupuesto de instintos o pulsiones biológicos. En un segundo momento, reconstruimos los aportes a partir de 1920 de la fenomenología genética para la teoría de la empatía husserliana. Estos aportes fueron considerados como el segundo gran hito de las reflexiones de Husserl sobre la empatía. Definimos el concepto de sintesis pasivas nacido del enfoque genético y su aplicación en la parificación empática. Nos encargamos cuidadosamente de describir las sintesis asociativas de la reproducción y de la inducción en su función de pre-configurar la experiencia objetiva de la conciencia yoica, y ulteriormente precisamos su funcionamiento en la pre-donación del otro durante la empatía denominada "inauténtica" o "impropia". Por último, sostuvimos y defendimos la tesis de que ciertas ideas originales de las teorias de Erdmann/ Mill y Lipps son recuperadas por Husserl en este nuevo período de los estudios de la intersubjetividad: particularmente, la indispensabilidad de una función de tipo analógica en relación con los primeros autores y la intuición de que la empatía no es un acto racional y voluntario del yo en relación con el último. 
Ahora bien, para comprender por completo la teoría husserliana de la empatía, aún restaría abordar un tema apenas mencionado de pasada en este artículo, a saber, la cuestión de la protoempatía (Ereinfühlung). Esta remite a los confines de la vida consciente: no solo compete al dominio de los protoinstintos del pre-yo sino también incluso a la temática del tiempo absoluto y el presente viviente, elaborada en los denominados Manuscritos del Grupo C de los años 1929-1934. Allí Husserl se pregunta: “¿Pertenece a la protocontinuación (retención) inherente a cada presente fluyente también una protoempatía (Ureinfühlung), o más bien, en lugar de una empatía que es explicitante, una protointencionalidad de la manifestación de una continuidad con los otros, que, como la fusión temporalizante, es mediata, continuamente mediata, en cuanto que ad-presentante?"68.

Esta pregunta inaugura el tercer hito cardinal de las reflexiones husserlianas sobre la intersubjetividad, pues la protoempatía propone un tipo de apercepción que no está dirigida a otro yo puntal, y por ende no necesita de la mediación de un cuerpo, sino que apunta a un curso intersubjetivo pre-temporal al interior de la intencionalidad longitudinal del curso absoluto del tiempo de la conciencia. Esta protoapercepción empatizante es efectivamente la condición de posibilidad última de los dos tipos de empatía (inauténtica y auténtica) expuestas en este trabajo. Así se comprueba que, como hemos adelantado en la introducción, la problemática de la intersubjetividad en Husserl no se reduce en absoluto a la clásica presentación de la teoría de la empatía en la "Meditación quinta". Esta posee, por un lado, toda una historia previa de discusiones con otras doctrinas rivales contemporáneas $\mathrm{y}$, por otro lado, se sostiene sobre profundas raíces que recién son desenterradas por los análisis de una fenomenología de la génesis y la generación de la mónada desde su nacimiento (o despertar consciente) hasta su muerte (o vuelta al sueño inconsciente).

Recibido: 10/05/2018

Aceptado: 14/12/2018

${ }^{68}$ HuaM VIII, p. 437. 


\section{Bibliografia}

Crespo, M., "Prolegómenos de una fenomenología de la compasión", El valor ético de la afectividad: Estudios de ética fenomenológica, Santiago de Chile: Ediciones Universitarias de Chile, 2012, pp. 85-98.

Erdmann, B., Wissenschaftliche Hypothesen über Leib und Seele: Vorträge gehalten an der Handelshochschule zu Köln, Colonia: Dumont, Schauberg, 1907.

Gurwitsch, A., Die mitmenschlichen Begegnungen in der Milieuwelt, Métraux, A. (ed.), Berlin/Nueva York: de Gruyter, 1977.

Husserl, E., Analysen zurpassiven Synthesis: Aus Vorlesungs-und Forschungsmanuskripten 1918-1926, Husserliana XI, ed. M. Fleischer, La Haya: Nijhoff, 1966.

, Briefwechsel. Band V. Die Neukantianer, Boston: Kluwer, 1994.

Experiencia y juicio, trad. México: Universidad Nacional de México, 1980.

Ideen zu einer reinen Phänomenologie und phänomenologischen Philosophie II: Phänomenologische Untersuchungen zur Konstitution, Husserliana IV, ed. M. Biemel, La Haya: Nijhoff, 1952; Ideas relativas a una fenomenología pura y una filosofia fenomenológia. Libro Segundo: Investigaciones fenomenológicas sobre la constitución, trad. México: Fondo de Cultura Económica, 2005.

, Ideen zu einer reinen Phänomenologie und phänomenologischen Philosophie III: Die Phänomenologie und die Fundamente der Wissenschaften, Husserliana V, ed. M. Biemel, La Haya, Nijhoff, 1952M Ideas relativas a una fenomenología pura y una filosofia fenomenológica. Libro Tercero: La fenomenología y los fundamentos de la ciencia, González, L.E. (trad.), México D.F.: UNAM, 2000

Investigaciones lógicas, García Morente, M. y J. Gaos (trads.), Madrid: Alianza Editorial, 2 vv., 2006.

, Lógica formal y lógica trascendental, Villoro, L. (trad.), México D.F.: CEF-UNAM, 1962.

, Meditaciones cartesianas, Gaos, J. y M. García-Baró (trads.), México D.F.: Fondo de Cultura Económica, 2005.

Späte Texte über Zeitkonstitution (1929-1934). Die C-Manuskripte, Husserliana Materialien IIX, ed. D. Lohmar, Nueva York: Springer, 2006.

Sur l'intersubjectivité, Depraz, N. (trad.), París: Presses Universitaires de France, 2 vv., 2001.

, Zur Phänomenologie der Intersubjektivität. Erster Teil: 1905-1920, Husserliana XIII, ed. I. Kern, La Haya: Nijhoff, 1973.

Zur Phänomenologie der Intersubjektivität. Zweiter Teil: 1921-1928, Husserliana XIV, ed. I. Kern, La Haya: Nijhoff, 1973.

, Zur Phänomenologie der Intersubjektivität. Dritter Teil: 1929-1935, Husserliana XV, ed. I. Kern, La Haya: Nijhoff, 1973.

Iribarne, J.V., La intersubjetividad en Husserl: Bosquejo de una teoría, 2 vols., Buenos Aires: Ediciones Carlos Lohlé, 1987.

Lipps, T, "Das Wissen von Fremden Ichen”, en: Psychologische Untersuchungen, 1 (1907), pp. 694-722.

, Leitfaden der Psychologie, Leipzig: Engelmann, 1909.

ARETÉ Revista de Filosofía, vol. XXXI, N², 2019 / ISSN 1016-913X 
Mill, J., An examination of Sir William Hamilton's philosophy, and of the principal philosophical questions discussed in his writings, Londres: Longman, Green, Longman, Roberts \& Green, 1865.

Osswald, A.M., Fundamentación pasiva de la experiencia: Un estudio sobre la fenomenología de Edmund Husserl, Madrid: Plaza y Valdés, 2016.

Scheler, M., Esencia y forma de la simpatia, Gaos, J. (trad.), Buenos Aires: Losada, 1957. Zur Phänomenologie und Theorie der Sympathiegefühle und von Liebe und Hass: Mit einem Anhang über den Grund zur annahme der Existenz des fremden Ich, Halle: Niemeyer, 1913.

Wesen und Formen der Sympathie - Die deutsche Philosophie der Gegenwart en: Frings, M. (ed.), Gesammelte Werke, v. 7, Berna: Francke, 1973.

Stein, E., Sobre el problema de la empatía, Caballero Bono, J.L. (trad.), Madrid: Trotta, 2004.

Zum Problem der Einfühlung, Múnich: Verlagsgesellschaft Gerhard Kaffke mbH, 1917.

Stueber, K., "Empathy", The Stanford Encyclopedia of Philosophy (Spring 2017 Edition), Edward N. Zalta (ed.), URL = <https://plato.stanford.edu/archives/spr2017/ entries/empathy/>.

Titchener, E.B., Lectures on the experimental psychology of the thought-processes, Nueva York: The Macmillan Company, 1909.

Walton, R.J., Intencionalidad y horizontalidad, Bogotá: Editorial Aula de Humanidades, 2015.

"Instintos, generatividad y tensión en la fenomenología de Husserl", Natureza humana, v. IV, 2 (2002), pp. 253-292.

Zahavi, D., Self and Other: Exploring Subjectivity, Empathy, and Shame, Nueva York: Oxford University Press, 2014. 